
B ulletin of
$\mathbf{M}$ anagement \&
B usiness
ISSN-p:
ISSN-e:
DOI:

\title{
Pengenalan Produk dan Promosi Alat Berat Hydraulic Excavator
}

\section{Nugroho Setio Aji ${ }^{1}$}

\begin{abstract}
Abstrak
Penelitian ini menjelaskan produk dari alat berat Hydraulic Excavator tipe 320D2. Penelitian kualitatif dengan pendekatan literatur. Pengumpulan data diperoleh dari hasil penelitian tesis, dan disertasi serta media elektronik.

Hasil penelitian menunjukkan bahwa fitur produk yang dimiliki alat berat Hydraulic Excavators tipe 320D2 yaitu teknologi, perceived usefulness, dan Convenience of use. Adapun kualitas produk, brand utility, aksesoris, dan jaminan. Pada promosinya alat berat Hydraulic Excavators tipe 320D2 GC terdapat Special offers, Endorsement, Joint ventures, dan Campaign.

Keterbatasan/Implikasi pada penelitian adalah sebatas pengenalan produk dan promosi sehingga penelitian selanjutnya perlu menindak lanjuti penelitian ini.

Kata Kunci: Produk, Promosi

Abstract

This research explains 320D2 GC Hydraulic Excavators. This study uses a qualitative method with a literature approach. Data collection was obtained from several sources from scientific books, research reports, scientific essays, theses and dissertations, regulations, provisions, yearbooks, encyclopedias, and sources which cannot be discussed accurately electronically.

The results showed that the product features possessed by Hydraulic Excavators type 320D2 GC are technology, perceived usability, and convenience of use. As for product quality, brand utility, accessories, and guarantees. In the promotion of 320D2 Hydraulic Excavators heavy equipment there are special offers, support, joint ventures, and campaigns.

Limitations / Implications for research are limited to product introduction and promotion so further research needs to follow up on this research using different research methods.
\end{abstract}

Keyword: product, promotion

\footnotetext{
${ }^{1}$ Fakultas Ekonomi, Universitas Brawijaya, Malang
} 


\section{PENDAHULUAN}

Alat berat merupakan kebutuhan khusus, dimana produknya memiliki spesifikasi tersendiri setiap tipenya, lebih spesifik, memiliki fungsi yang berbeda setiap tipenya, dan memiliki konsumen yang khusus pula yang bergerak dibidang konstruksi (Agustiono, et al., 2016). Salah satu cara untuk dapat membeli alat berat tersebut, konsumen harus mengenal produk dan sistem promosinya terlebih dahulu.

Barang atau produk adalah benda yang mampu ditawarkan kepada konsumen agar dapat digunakan untuk memenuhi kebutuhan (Amstrong dan Kotler, 2011; Kotler dan Keller, 2016). Promosi adalah alat untuk mengenalkan produk baru kepada konsumen agar dapat dibeli oleh konsumen (Kotler dan Keller, 2012).

Pada penelitian ini lebih difokuskan menganalisis pemasaran yaitu product (Produk) dan promotion (Promosi), dimana kedua variabel tersebut merupakan variabel yang terdapat di tempat subyek penelitian dan sesuai dengan karakter di tempat subyek penelitian yang akan diteliti sebagai faktor yang mendorong motivasi konsumen untuk melakukan keputusan pembelian alat berat pada PT. Trakindo Cat. Namun, pada price (Harga) dan place (Tempat) tidak menjadi fokus penelitian ini berdasarkan pada karakter produk yang ditawarkan, dikarenakan price tidak diterapkan pada perusahaan tersebut, mengingat price (harga) alat berat PT Trakindo Cat selalu menjadi leader bagi kompetitor lainnya. berdasarkan riset perusahaan, jika harga PT Trakindo berubah, maka kompetitor alat berat lainnya akan ikut berubah. Penetapan penurunan price (harga) pada penjualan alat berat juga mengindikasikan penurunan kualitas alat berat. Selanjutnya, yang tidak menjadi fokus pada penelitian ini yaitu place (Tempat).

Place (Tempat) dianggap pula tidak signifikan dalam persaingan alat berat. Karakter konsumen alat berat memiliki ciri khas bahwa ketika konsumen membutuhkan barang tersebut, dimanapun tokonya pasti akan dicari. Demikian halnya dengan strategi mendekati pasar, dealer tidak bisa terlalu mendekati pasar yang tersebar secara luas pada berbagai daerah di Indonesia. Dapat dikatakan bahwa place (Tempat) tidak efektif dalam memperluas pangsa pasar alat berat. Maka dari itu, salah satu faktor yang membuat keputusan pembelian alat berat yaitu kebutuhan produk.

Kebutuhan produk merupakan sesuatu yang dibutuhkan oleh konsumen yang dapat diakomodir oleh barang atau jasa yang bisa ditawarkan ke pasar guna memuaskan keinginan atau kebutuhan. Produk merupakan segala sesuatu yang dapat ditawarkan kepasar untuk mendapatkan perhatian, dibeli, digunakan, atau dikonsumsi yang dapat memuaskan keinginan atau kebutuhan (Kotler dan Amstrong, 2001). Lini produk alat berat CATERPILLAR cukup lengkap, mulai dari Articulated Trucks, Backhoe Loader, Drill Machines, Genset, Marine Engine, Forest Products, Hydraulic Excavators, Material Handlers, Mining \& Off Highway Trucks, Motor Graders, Paving Products, Pipe Layers, Skid Steer Loaders, Multi Terrain Loaders, Compact Track Loaders, Telescopic Handlers, Track Loaders, Track Type Tractors, Wheel Dozers, Wheel Loaders, Underground Mining Equipments, Forklift Trucks, dan masih banyak lagi (PHB, 2016).

Produk yang dimaksud merupakan produk alat berat Hydraulic Excavator merek Caterpillar kelas 20 ton. Hydraulic excavator merupakan alat serba guna yang dapat digunakan untuk menggali tanah (digging), memuat material ke dump truck (loading), mengangkat material (lifting), mengikis tebing (scraping), membuat saluran (trenching) dan meratakan (grading). Dengan menggunakan kombinasi penggantian alat 


\section{B ulletin of

kerja (worktools), maka dapat digunakan untuk memecah batu (breaking), membongkar aspal, dan lain-lain. Excavator tipe 320D2 merupakan excavator yang direkayasa untuk performa kerja tinggi yang mengutamakan efisiensi kerja dan produktivitas tinggi, berorientasi pada target ton/jam dan penggunaan jam kerja yang tinggi pertahunnya (diatas $2000 \mathrm{jam} / \mathrm{tahun}$ ). Excavator tipe 320D2GC merupakan excavator yang direkayasa untuk aplikasi pekerjaan yang mengutamakan biaya operasional yang murah perjamnya, konsumsi bahan bakar yang rendah, dengan utilisasi alat dibawah 2000 jam per tahunnya. Dengan dibuatnya dua varian produk ini diharapkan Caterpillar bisa menguasai pasar secara keseluruhan dan bisa meningkatkan penjualan alat berat excavator kelas 20 ton.

Promosi yang dilakukan PT. Trakindo untuk menarik minat beli konsumen dilakukan dengan berbagai cara antara lain pameran yang dilakukan setiap tahun di acara Mining Exhibition, dan Construction Exhibition. PT Trakindo Utama juga melakukan promosi di setiap kantor region dengan cakupan konsumen yang lebih kecil dengan harapan meningkatkan hubungan baik antara konsumen dan distributor. Selain melalui tatap muka dalam bentuk pameran, PT Trakindo Utama juga mempromosikan produknya melalui website, email, instagram, facebook, whatapps, dan media online lainnya sesuai dengan perkembangan jaman saat ini.

Tujuan penelitian ini adalah menjelaskan produk dari alat berat Hydraulic Excavators kelas 20 ton menggunakan metode kualitatif dengan pendekatan literatur.

\section{KAJIAN PUSTAKA}

Srategi Marketing Mix

Menurut American Marketing Association mengungkapkan bahwa "marketing is the process of planning and executing the conception, pricing, promotion, and distribution of ideas, goods, and services to create exchange that satisfy individual and organizational goals". Dapat dikatakan pemasaran memiliki dua dimensi yaitu dimensi filosofis pada kepuasan konsumen dan dimensi implementatif filosofi tersebut.

Pemasaran adalah salah satu alat strategi yang menghubungkan produsen dengan pelanggan sehingga memudahkan produsen untuk mencapai tujuannya, baik tujuan jangka pendek maupun jangka panjang. Pemasaran menjadi penting tatkala semakin banyaknya pesaing yang memproduksi beranekaragam produk yang diinginkan oleh konsumen. Pemasaran merupakan salah satu strategi yang dapat membantu perusahaan dalam memenangkan persaingan.

Pemasaran adalah suatu proses sosial yang didalamnya individu dan kelompok mendapatkan apa yang mereka butuhkan dan inginkan dengan menciptakan, menawarkan, dan secara bebas mempertukarkan produk yang bernilai dengan pihak lain (Kotler dan Keller, 2016). Asosiasi pemasaran di Amerika mendefinisikan pemasaran sebagai salah satu fungsi organisasi dan seperangkat proses untuk menciptakan, mengomunikasikan dan menyerahkan nilai kepada pelanggan dalam mengelola hubungan pelangan dengan cara yang menguntungkan organisasi dan para pemilik sahamnya.

Stanton (2001) dan Husein (2000) mendefinisikan bahwa pemasaran sebagai bentuk dari sistem yang berhubungan dengan kegiatan usaha yang bertujuan merencanakan, menentukan harga, hingga mempromosikan dan mendistribusikan barang atau jasa yang akan memuaskan kebutuhan pembeli baik aktual maupun yang potensial. Dari definisi ini disimpulkan bahwa jangkauan pemasaran sangat luas dan ada 


\section{B ulletin of

berbagai tahapan kegiatan yang harus dilalui sebelum sampai ke tangan konsumen. Terdapat empat komponen pokok dalam konsep pemasaran, yaitu: 1) Sasaran Pasar, pasar terdiri dari banyak pembeli yang berbeda dalam beberapa hal misalnya keinginan, kemampuan, keuangan, lokasi dan sikap pembeli. Dari berbagai perbedaan ini dapat dilakukan analisis untuk memilih sasaran pasar. Ada beberapa faktor yang dapat digunakan dalam menganalisis segmen pasar, seperti ukuran dan pertumbuhan segmen, menariknya segmen serta sasaran dan sumber daya yang dimiliki perusahaan; 2) Kebutuhan pelanggan, perusahaan diharapkan mampu memahami kebutuhan pelanggan sehingga dapat memuaskannya. (Kotler dan Keller, 2016) membedakan kebutuhan pelanggan ke dalam lima jenis, yaitu: a)Kebutuhan yang diutarakan (pelanggan menginginkan produk yang murah; b) Kebutuhan nyata (pelanggan menginginkan produk dengan biaya operasi yang rendah, bukannya harga beli yang murah); c) Kebutuhan yang tidak diutarakan (pelanggan mengharapkan pelayanan yang baik dari penyalur); d) Kebutuhan kegembiraan (pelanggan membeli produk dengan tambahan fitur-fitur berhadiah khusus); dan d) Kebutuhan rahasia (pelanggan ingin dipandang sebagai konsumen yang cerdas dan berorientasi nilai); 3) Pemasaran terpadu, hal ini tercipta apabila semua departemen dalam perusahaan bekerja sama untuk melayani kepentingan pelanggan. Pemasaran terpadu dapat terjadi dalam dua tahap yaitu keberagaman fungsi pemasaran yang saling bersineergi dan dikoordinasikan dengan baik oleh bagian lain perusahaan; dan 4) Profitabilitas, merupakan tujuan perusahaaan disamping meraup laba juga memberikan pelayanan secara memuaskan pada pelanggan.

Strategi pemasaran memegang peranan penting dalam rencana pemasaran oleh karenanya strategi ini harus disusun secara jelas dan dapat memberi gambaran yang terarah tentang apa yang dilakukan perusahaan dalam menggunakan setiap kesempatan atau peluang pada pasar yang disasar. Oleh karenanya dalam strategi pemasaran terdapat dua komponen utama yaitu pasar yang dituju (target market) dan pemasaran yang dijalankan (marketing mix) untuk merebut sasaran pasar tersebut.

Bauran pemasaran merupakan perangkat/alat pemasar yang terdiri atas berbagai unsur satu program pemasaran yang perlu dipertimbangkan agar implementasi strategi pemasaran dan penentuan posisi yang ditetapkan dapat berjalan sukses (Lupiyoadi, 2014).

Pengertian bauran pemasaran menurut Zeithaml dan Bitner (2013) merupakan elemen organisasi perusahaan yang dapat dikontrol oleh perusahaan dalam melakukan komunikasi dengan konsumen dan akan dipakai untuk memuaskan konsumen. Marketing mix dicirikan dari adanya unsur pemasaran terkait yang dibaurkan, diorganisir dan digunakan dengan tepat sehingga perusahaan dapat mencapai tujuan pemasaran dengan efektif sekaligus memuaskan kebutuhan dan keinginan konsumen.

\section{Produk}

Barang atau produk adalah benda yang mampu ditawarkan kepada konsumen agar dapat digunakan untuk memenuhi kebutuhan (Amstrong dan Kotler, 2011; Kotler dan Keller, 2016). Produk adalah segala sesuatu yang dapat ditawarkan ke pasar untuk mendapatkan perhatian, dibeli, digunakan, atau dikonsumsi yang dapat memuaskan keinginan atau kebutuhan. Secara konseptual produk adalah pemahaman subyektif dari produsen atas sesuatu yang bisa ditawarkan sebagai usaha untuk mencapai tujuan organisasi melalui pemenuhan kebutuhan dan kegiatan konsumen, sesuai dengan kompetensi dan kapasitas organisasi serta daya beli pasar. Selain itu, produk dapat pula 


\section{B ulletin of

didefinisikan sebagai persepsi konsumen yang dijabarkan oleh produsen melalui hasil produksinya (Amstrong dan Kotler, 2011). Agar produk yang dihasilkan dapat memuaskan konsumen, maka harus melakukan penambahan nilai kegunaan dari produk dengan cara menambahkan fitur produk yang terdapat pada alat berat tersebut (Alma, 2018).

\section{Promosi}

Promosi adalah alat untuk mengenalkan produk baru kepada konsumen agar dapat dibeli oleh konsumen (Kotler dan Keller, 2012). Tjiptono (2008) promosi adalah suatu bentuk komunikasi pemasaran yang dimaksud dengan komunikasi pemasaran adalah aktivitas pemasaran yang berusaha menyebarkan informasi, mempengaruhi / membujuk dan mengingatkan pasar sasaran atas perusahaan dan produknya agar bersedia menerima, membeli dan loyal pada produk yang ditawarkan perusahaan yang bersangkutan. Bentuk promosi dapat berupa personal selling; mass selling dan direct marketing (Amstrong dan Keller, 2011).

\section{Hydraulic Excavators tipe 320D2}

Excavator tipe 320D2 merupakan excavator yang direkayasa untuk performa kerja tinggi yang mengutamakan efisiensi kerja dan produktivitas tinggi, berorientasi pada target ton/jam dan penggunaan jam kerja yang tinggi pertahunnya (diatas 2000 jam/tahun). Excavator tipe 320D2GC merupakan excavator yang direkayasa untuk aplikasi pekerjaan yang mengutamakan biaya operasional yang murah perjamnya, konsumsi bahan bakar yang rendah, dengan utilisasi alat dibawah 2000 jam per tahunnya. Dengan dibuatnya dua varian produk ini diharapkan Caterpillar bisa menguasai pasar secara keseluruhan dan bisa meningkatkan penjualan alat berat excavator kelas 20 ton.

\section{METODE PENELITIAN}

Penelitian ini menggunakan kualitatif dengan pendekatan interpretatif,. Setting penelitian dilakukan di PT. Trakindo Surabaya. Pengumpulan data diperoleh dari wawancara, observasi, dan memo (Hamzah, 2019). Keabsahan data menggunakan credibility, transferability, dan confrimability (Neuman, 2014).

\section{HASIL DAN PEMBAHASAN}

Pemasaran adalah suatu proses sosial yang didalamnya individu dan kelompok mendapatkan apa yang mereka butuhkan dan inginkan dengan menciptakan, menawarkan, dan secara bebas mempertukarkan produk yang bernilai dengan pihak lain (Kotler dan Keller, 2016). Stanton (2001) dan Husein (2000) mendefinisikan bahwa pemasaran sebagai bentuk dari sistem yang berhubungan dengan kegiatan usaha yang bertujuan merencanakan, menentukan harga, hingga mempromosikan dan mendistribusikan barang atau jasa yang akan memuaskan kebutuhan pembeli baik aktual maupun yang potensial.

Strategi pemasaran memegang peranan penting dalam rencana pemasaran oleh karenanya strategi ini harus disusun secara jelas dan dapat memberi gambaran yang terarah tentang apa yang dilakukan perusahaan dalam menggunakan setiap kesempatan atau peluang pada pasar yang disasar. Oleh karenanya dalam strategi pemasaran 
terdapat dua komponen utama yaitu pasar yang dituju (target market) dan pemasaran yang dijalankan (marketing mix) untuk merebut sasaran pasar tersebut.

Bauran pemasaran merupakan perangkat/alat pemasar yang terdiri atas berbagai unsur satu program pemasaran yang perlu dipertimbangkan agar implementasi strategi pemasaran dan penentuan posisi yang ditetapkan dapat berjalan sukses (Lupiyoadi, 2014). Salah satu untuk dapat mengenalkan barang dapat menggunakan teknik pengenalan terhadap produk.

Produk dapat dikatakan sebagai barang yang dapat dibeli untuk pemenuhan kebutuhan individu atau kelompok (Kotler dan Keller, 2016). Produk yang dimaksud dalam penelitian ini merupakan produk alat berat. Alat berat adalah mesin berukuran besar yang didesain untuk melaksanakan fungsi konstruksi seperti pengerjaan tanah (earthworking) dan memindahkan bahan bangunan (earthmoving).

Alat berat umumnya terdiri atas lima komponen, yaitu implemen, alat traksi, struktur, sumber tenaga dan transmisinya (power train), serta sistem kendali. Alat berat dapat digunakan oleh manusia sebagai alat bantu dalam mengerjakan pekerjaan yang berat seperti pertambangan, pekerjaan perhutanan dan perkebunan, serta konstruksi. Alat berat yang paling sering dipergunakan untuk membantu melakukan pekerjaan-pekerjaan tersebut adalah Hydraulic Excavator. Pada dasarnya Hydraulic Excavator merupakan alat berat yang berfungsi untuk menggali (excavating), namun tidak jarang juga excavator digunakan untuk menaikkan material ke dalam truk (loading) dan memecah batu (breaking).

Secara umum, Excavator terdiri dari beberapa bagian yaitu: Bucket, adalah bagian yang digunakan untuk mengeruk dan memindahkan material. Bucket Cylinder, adalah bagian yang digunakan untuk menggerakkan bucket. Arm/Stick, adalah bagian yang digunakan untuk menaikkan dan menurunkan bucket Arm/Stick Cylinder, adalah bagian yang digunakan untuk menggerakkan arm/stick. Boom, adalah bagian yang digunakan untuk menaikkan dan menurunkan arm/stick. Boom cylinde, adalah bagian yang digunakan untuk menggerakkan boom. Cabin, adalah tempat operator Excavator bekerja menggerakkan excavator. Didalamnya terdapat alat kendali dan indikatorindikator yang bisa digunakan oleh omperator untuk mengendalikan excavator dan juga mengetahui kondisi awal dari excavator tersebut. Engine dan pompa hidrolik, adalah penggerak dari excavator. Engine yang digunakan biasanya menggunakan diesel engine dan pompa hidrolik yang digunakan biasanya menggunakan piston pump. Engine akan menggerakkan pompa hidrolik yang kemudian menyirkulasikan oli hidrolik ke bagianbagian yang diinginkan untuk menggerakkan excavator. Track adalah bagian yang berfungsi sebagai roda. Propel/ Final Drive, adalah bagian yang berfungsi untuk menggerakkan track. Upper structure, merupakan struktur bagian atas dari excavator dimana bucket, stick, boom, cabin, engine dipasang. Upper structure bisa berputar 360 derajat. Undercarriage, adalah bagian bawah excavator dimana propel dan track dipasang. Undercarriage berfungsi sebagai penopang dari upper structure.

Lini produk alat berat CATERPILLAR cukup lengkap, mulai dari Articulated Trucks, Backhoe Loader, Drill Machines, Genset, Marine Engine, Forest Products, Hydraulic Excavators, Material Handlers, Mining \& Off Highway Trucks, Motor Graders, Paving Products, Pipe Layers, Skid Steer Loaders, Multi Terrain Loaders, Compact Track Loaders, Telescopic Handlers, Track Loaders, Track Type Tractors, Wheel Dozers, Wheel Loaders, Underground Mining Equipments, Forklift Trucks, dan masih banyak lagi (PHB, 2016). 
Produk alat berat Hydraulic Excavators tipe 320D2 GC memiliki beberapa fitur produk, yaitu Teknologi yang digunakan pada produk Hydraulic Excavators tipe 320D2 GC merupakan yang terbaik di bidangnya, Performa dari produk Hydraulic Excavators tipe 320D2 GC sangat bagus. Selain, teknologinya juga terdapat Perceived usefullness yang mudah dipelajari dan mudah dioperasionalkan oleh pekerja. Selanjutnya, pada Convenience of use adalah produk yang dapat diandalkan diberbagai medan dan memiliki perawatan yang lebih mudah.

Kualitas produk yang dimiliki lebih tahan lama dibandingkan dengan merk lain dan memiliki akselerasi yang bagus. Serta, Lebih besar digging force, lebih cepat bongkar, lebih produktif dan Swing lebih cepat, cycle time lebih cepat, lebih produktif. Untuk brand utilitynya produk Hydraulic Excavators tipe 320D2 GC lebih hemat bahan bakar. Bahkan, Aksesoris yang berupa suku cadang lebih mudah didapat dan memiliki banyak varian di unit bucket. Jaminannya memiliki jangka waktu yang lama dan memiliki kehandalan yang baik. Produk dapat dibeli bila terdapat sistem promosi yang baik.

Promosi adalah alat untuk mengenalkan produk baru kepada konsumen agar dapat dibeli oleh konsumen (Kotler dan Keller, 2012). Promosi yang dilakukan untuk menarik minat beli konsumen dilakukan dengan berbagai cara antara lain dengan mengikuti pameran besar pameran yang dilakukan setiap tahun di acara Mining Exhibition, dan Construction Exhibition untuk meningkatkan paparan produk kepada para pembeli alat berat. PT Trakindo Utama juga melakukan promosi di setiap kantor region dengan cakupan konsumen yang lebih kecil dengan harapan meningkatkan relasi antara konsumen dan distributor. Selain melalui tatap muka dalam bentuk pameran, mempromosikan produknya melalui website, email, instagram, facebook, Whatapp, dan media online yang lain mengikuti perkembangan jaman yang ada saat ini, mempromosikan produk-produknya dengan membuat paket-paket menarik seperti perpanjangan masa garansi sampai 2 tahun tanpa batasan jam, garansi konsumsi bahan bakar, paket kontrak servis, dan paket-paket menarik lainnya guna meningkatkan motivasi pelanggan untuk membeli produk-produk yang dijual.Bentuk promosi yang terdapat di perusahaan alat tersebut adalah Special Offers yang menawarkan harga khusus dan menawarkan produk baru secara berkala kepada perusahaan lain. Adapun bentuk Campaign yaitu secara rutin mengadakan event untuk mempromosikan produknya dan menjelaskan fungsi kegunaan dari alat berat yang disesuaikan dengan kondisi lingkungan pekerjaan. Serta terdapat Joint Ventures berupa penawaran untuk menjadi rekanan dan penawaran untuk menjadi mensponsori perusahaan.

\section{KESIMPULAN DAN SARAN}

Berdasarkan paparan hasil diatas diketahui bahwa produk dan promosi memiliki peranan yang penting dalam mengenalkan barang terutama pada alat berat. hal itu terbukti dengan adanya fitur produk, kualitas produk dan kehandalan produk. serta memiliki sistem promosi berupa special officers, Campaign, dan Join Ventures.

Penelitian berikutnya dapat menambahkan variabel baru yang terdapat di marketing mix seperti peran pentingnya tempat dan harga dalam bisnis pemasaran yang dapat terukur dan dapat dihitung. 


\section{REFERENSI}

Agustiono, A., Militina, T dan Rahmawati, I, 2016. Pengaruh Bauran Pemasaran terhadap Keputusan Pembelian Spare Part Undercarriage Komatsu di PT United Tractors Tbk Loa Janan Samarinda. Ekonomia Vol. 5, No 3.

Aji, N. S., Achmad H. D., and Ainur R. 2019. The Influence of Products and Promotions on Purchasing Decisions Mediated in Purchase Motivation. Jurnal Aplikasi Manajemen, Volume 17, Number 1, Pages 152-17. Malang: Universitas Brawijaya. http://dx.doi.org/10.21776/ub.jam.2019.017.01.17.

Alma, Buchari, 2018. Manajemen Pemasaran \& Pemasaran Jasa. Bandung: Alfabeta.

Amstrong, G dan Kotler, P. 2011. Marketing: An Introduction (10 Edition). Upper Saddle River, NJ: Pearson Prentice Hall.

Hamzah, Amir, 2019. Metode Penelitian Kepustakaan: Kajian Filosofi, Teoritis, dan Aplikatif. Literasi Nusantara.

Husein, Umar. 2000. Riset Pemasaran dan Perilaku Konsumen. PT. Gramedia Pustaka Utama, Jakarta.

Kotler, P. dan Keller, 2012. Marketing Management. Edisi keempatbelas. England: Pearson Education Limited.

Kotler, P. dan Keller, K. L., 2016, Marketing Management. Global Edition. 15e. PEARSON.

Lupiyoadi, Rambat. 2014. Manajemen Pemasaran Jasa. Edisi 3. Jakarta:Salemba Empat.

Neuman, W. L., 2014. Social Research Methods: Qualitative and Quantitative Approaches. Seventh Edition. Edinburgh Gate. Pearson Education Limited.

PHB 46, 2016. CATERPILLAR PERFORMANCE HANDBOOK. Caterpillar, Peoria, Illinois, U.S.A.

Stanton, Wiliam J., 2001. Dasar-Dasar Pemasaran. (terjemahan). Jilid I. Jakarta: Penerbit Erlangga.

Tjiptono, Fandy. 2008. Strategi Pemasaran, Edisi Ketiga. Andi, Yogyakarta.

Zeithaml, V.A., M.J. Bitner, D.D. Gremler. 2013. Services Marketing: Integrating Customer Focus Across the Firm 6 thed. Mc.Graw-Hill. Boston. 